\title{
Sistem Peringatan Dini Bencana Longsor Menggunakan Sensor Accelerometer dan Sensor Kelembaban Tanah Berbasis Android
}

\author{
Onny Octaviani Artha, Budi Rahmadya, Rahmi Eka Putri \\ Sistem Komputer Fakultas Teknologi Informasi Universitas Andalas, Kampus Limau Manis, Padang, 25163, Indonesia
}

\section{ARTICLE INFORMATION}

Received: August 11, 2018

Revised: Septembet 09, 2018

Available online: Septermber 29, 2018

\section{KEYWORDS \\ Landslide, MPU6050, soil movement, soil moisture}

\section{CORRESPONDENCE}

E-mail: budi-r@fti.unand.ac.id

\section{A B S T $\mathbf{T}$ A A C $\mathbf{T}$}

Landslide is one of the most frequent disasters in Indonesia, especially in hilly areas, valleys, and volcanoes. Geographical conditions that are generally mountainous areas and have slopes make the soil unstable. As a result, when the movement of the land becomes easy to slide. Ground shifts and excessive water content are the main causes of landslides. The landslide disaster can cause many losses, such as to cause loss of life, can disrupt transportation facilities, damage agricultural land, and various other consequences. In this study used sensor MPU6050 and Soil Moisture and NodeMcu sensors to provide early warning of landslides. Linear acceleration is detected by using MPU6050 sensor and will define the ground movement based on the scenarios developed in this study. Soil moisture sensor detects soil moisture. The result of soil movement detection and soil moisture is stored in file storage. When ground detection and soil moisture is greater than $51 \%$, the alarm alert is sent to the user's smartphone with a $100 \%$ success percentage.

\section{PENDAHULUAN}

Bencana longsor merupakan salah satu bencana yang sering terjadi di beberapa daerah di Indonesia, terutama di daerah perbukitan, lembah, dan gunung berapi. Kondisi tanah di sebagian wilayah Indonesia memang tergolong rawan longsor. Berdasarkan peta zona kerentanan bencana longsor menurut Badan Nasional Penanggulangan Bencana (BNBP) pada tahun 2013, terdapat 918 lokasi rawan longsor di Indonesia [1]. Kondisi geografis yang umumnya merupakan daerah pegunungan dan memiliki lereng-lereng menjadikan tanah tidak stabil. Akibatnya, ketika terjadi pergerakan tanah menjadi mudah longsor. Pergeseran tanah dan kadar air yang berlebih merupakan penyebab utama dari bencana longsor. Peristiwa longsor juga dipicu karena adanya gaya pendorong pada tanah. Pada prinsipnya, longsor terjadi karena faktor gaya pendorong lebih besar daripada gaya penahan [2].

Bencana longsor dapat menimbulkan banyak kerugian, diantaranya dapat menimbulkan korban jiwa, dapat mengganggu fasilitas transportasi, merusak lahan pertanian, dan berbagai akibat lainnya. Dampak dari tanah longsor ini dapat dihindari jika masyarakat mengetahui tanda-tanda terjadinya longsor dan mendapat peringatan bahwa akan terjadi longsor. Oleh sebab itu, diperlukan sistem peringatan dini bencana longsor. Dengan adanya sistem peringatan dini bencana longsor, bencana longsor dapat diantisipasi dan masyarakat lebih siap untuk menghadapi bencana longsor sehingga meminimalisir kerugian dan korban jiwa akibat bencana longsor.

Pada penelitian sebelumnya telah dirancang sistem peringatan dini tanah longsor menggunakan metode pengindraan berat dengan sistem sensor yang terdiri dari sebuah pegas dengan sebuah LED dilekatkan disalah satu ujung pegas dan fotodioda di ujung lainnya, sehingga dapat mengaktifkan indikator LED[3] . Penelitian lain merancang perangkat elektronik berupa gabungan sensor getaran dan kandungan air tanah. Model longsor dibuat pada suatu box dari bahan mika, dan material tanah. Hasil penelitian didapatkan berdasarkan kemiringan tanah [4]. Namun sistem ini memiliki kelemahan dari segi notifikasi, karena hanya memakai buzzer sebagai indikator tanda bahaya pada sistem dan memakai LCD sebagai antarmuka sistem.

Berdasarkan penelitian sebelumnya, maka dibutuhkan suatu peringatan dini bencana longsor yang dapat diakses langsung dan real time melalui aplikasi mobile, sehingga masyarakat dapat lebih waspada dan cepat mengantisipasi adanya korban akibat bencana longsor tersebut. Penulis menggunakan sensor accelerometer MPU6050 untuk mengukur getaran tanah dan sensor soil moisture untuk menukur kelembaban tanah. 


\section{STUDI PUSTAKA}

\subsection{Pengertian Tanah Longsor}

Tanah longsor merupakan proses perpindahan massa tanah atau batuan dengan arah miring dari kedudukan semula akibat adanya gaya gravitasi. Pengaruh gaya gravitasi mengakibatkan semakin curamnya lereng semakin besar pula kemungkinan material-material penyusun lereng tersebut jatuh ke tempat yang rendah. Perpindahan material total sebelum longsor bergantung pada besarnya regangan untuk mencapai kuat geser puncaknya dan pada tebal zona longsornya [5].

\subsection{NodeMcu}

Nodemcu merupakan sebuah open source platform IoT dan pengembangan kit yang menggunakan bahasa pemrograman Lua untuk membantu pengguna dalam membuat prototype produk IoT atau bisa dengan memakai sketch arduino IDE. Pengembangan Kit ini didasarkan pada modul ESP8266, yang mengintegrasikan GPIO, PWM (Pulse Width Modulation), I2C, 1-Wire dan ADC (Analog to Digital Converter) semua dalam satu board [9].

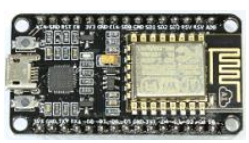

Gambar 2.1 Mikrokontroler NodeMcu [9]

\subsection{Sensor MPU6050}

MPU6050 merupakan perangkat Motion Tracking pertama di dunia yang terintegrasi 6 axis dengan menggabungkan 3 axis MPU6050 dan 3 axis gyroscope serta Digital Motion Processor yang semuanya dalam paket ukuran kecil, 4x4x0.9 mm. Sensor MPU6050 dilengkapi dengan tiga konverter ADC (Analog Digital Converter) 16 bit untuk mengkonversi keluaran gyroscope dan tiga konverter ADC 16 bit untuk mengkonversi keluaran MPU6050. Untuk mengetahui presisi baik cepat ataupun lambat gerakan, gyroscope diprogram dengan dengan penggunaan full scale berkisar antara $\pm 250, \pm 500, \pm 1000$, dan $\pm 2000^{\circ} /$ detik (dps) dan pada MPU6050 diprogram dengan penggunaan full scale berkisar antara $\pm 2 \mathrm{~g}, \pm 4 \mathrm{~g}, \pm 8 \mathrm{~g}$, dan \pm $16 \mathrm{~g}$. MPU6050 beroperasi pada tegangan $2.375 \mathrm{~V}-3.46 \mathrm{~V}$. MPU6050 hanya mendukung Serial Interface [10]. Beberapa fitur yang tedapat pada sensor MPU6050 adalah sebagai berikut:
a. Fitur Gyroscope pada MPU6050
a. Digital output X-, Y- dan Z- gyroscope mempunyai range full scale $\pm 250, \pm 500, \pm 1000, \pm 2000^{\circ} /$ detik
b. ADC 16 bit pada gyroscope memungkinkan pengambilan sampel gyroscope secara simultan.
c. Beroperasi pada arus $3.6 \mathrm{~mA}$
b. Fitur Accelerometer pada MPU6050
a. Digital output X-, Y-dan Z- MPU6050 mempunyai full scale range $\pm 2, \pm 4, \pm 8, \pm 16 \mathrm{~g}$.
b. ADC 16 bit pada MPU6050 memungkinkan pengambilan sampel MPU6050 secara simultan tanpa harus menggunakan multiplekser
c. MPU6050 beroperasi pada arus $500 \mu \mathrm{A}$

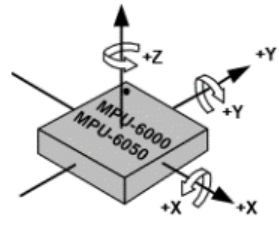

Gambar 2.2 Sensor MPU6050 [10]

\subsection{Sensor Soil Moisture}

Sensor soil moisture adalah sensor kelembaban yang dapat mendeteksi kelembaban dalam tanah [11]. Sensor ini sangat sederhana, tetapi ideal untuk memantau kelembaban tanah. Sensor ini terdiri dua probe untuk melewatkan arus melalui tanah, kemudian membaca resistansinya untuk mendapatkan nilai tingkat kelembaban. Semakin banyak air membuat tanah lebih mudah menghantarkan listrik (resistansi kecil), sedangkan tanah yang kering sangat sulit menghantarkan listrik (resistansi besar). Sensor ini sangat membantu untuk mengingatkan tingkat kelembaban pada tanaman atau memantau kelembaban tanah [12].

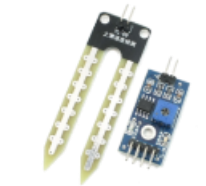

\section{Gambar 2.3 Sensor Soil Moisture [12]}

Sebagai standar dalam mengukur kelembaban tanah, pada penelitian ini digunakan American Standard Method (ASM). Prinsip dari American Standard Method (ASM) adalah dengan cara melakukan perbandingan antara massa air (MA) dengan massa tanah kering (MTK) yang telah dibahas sebelumnya Massa air (MA) didapatkan dari massa tanah basah (MTB) dikurangi dengan massa tanah kering (MTK) [21]. Untuk dapat mengetahui kondisi kelembaban tanah dapat dilakukan pengukuran secara manual. Persamaan yang digunakan untuk mengetahui kelembaban tanah ditunjukkan persamaan 2.4 dan persamaan 2.5

$$
\begin{aligned}
& M A=M T B-M T K \\
& K T=\frac{M A}{M T K} \times 100 \%
\end{aligned}
$$

\section{PERANCANGAN SISTEM}

\subsection{Analisis Kebutuhan Sistem}

Kebutuhan fungsional yang dibutuhkan pada sistem peringatan dini bencana longsor berbasis android adalah:

a. Sistem dapat membaca data dari sensor MPU6050 dan sensor soil moisture.

b. Sistem dapat menerima data dari sensor MPU6050 dan sensor soil moisture yang akan dikirimkan melalui NodeMcu ke aplikasi mobile.

c. Sistem dapat memberikan peringatan dan informasi adanya kemungkinan bencana longsor melalui aplikasi mobile.

Adapun kebutuhan non fungsionalitas agar sistem dapat berjalan dengan baik adalah kondisi jaringan yang stabil.

\subsection{Rancangan Umum Sistem}

Adapun rancangan proses pada sistem ini dapat dilihat pada gambar 3.1. 


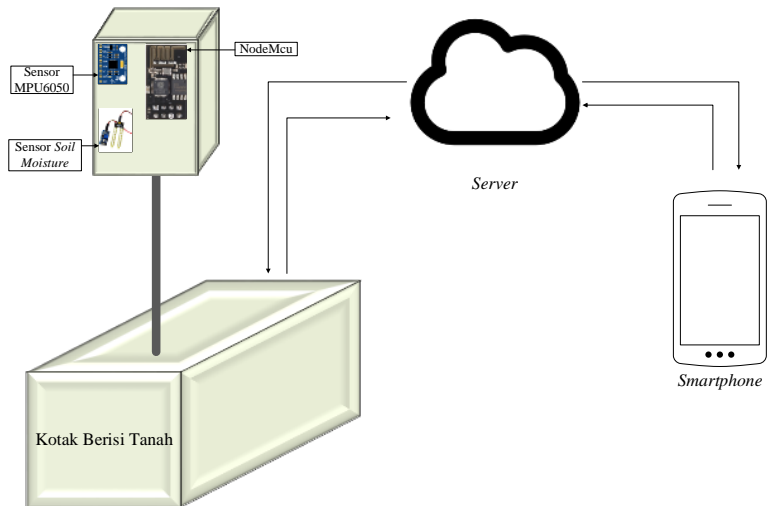

Gambar 3.1 Gambaran Umum Sistem

Prinsip kerja dari sistem peringatan dini bencana longsor berbasis android adalah:

a. Sensor accelerometer MPU6050 merupakan sensor yang dapat memabaca pergerakan tanah.

b. Sensor soil moisture merupakan sensor yang dapat membaca kelembaban tanah.

c. NodeMcu merupakan mikrokontroler yang akan ditanamkan program sehingga sistem dapat memantau keadaan tebing.

d. File penyimpanan digunakan untuk tempat penyimpanan data pergerakan tanah, kelembaban tanah, dan status tebing aman atau bahaya yang telah didefinisikan oleh mikrokontroler.

e. Smartphone digunakan untuk menampilkan peringatan dini bencana longsor.

\subsection{Rancangan Proses}

Adapun rancangan proses pada sistem ini dapat dilihat pada gambar 3.2 adalah :

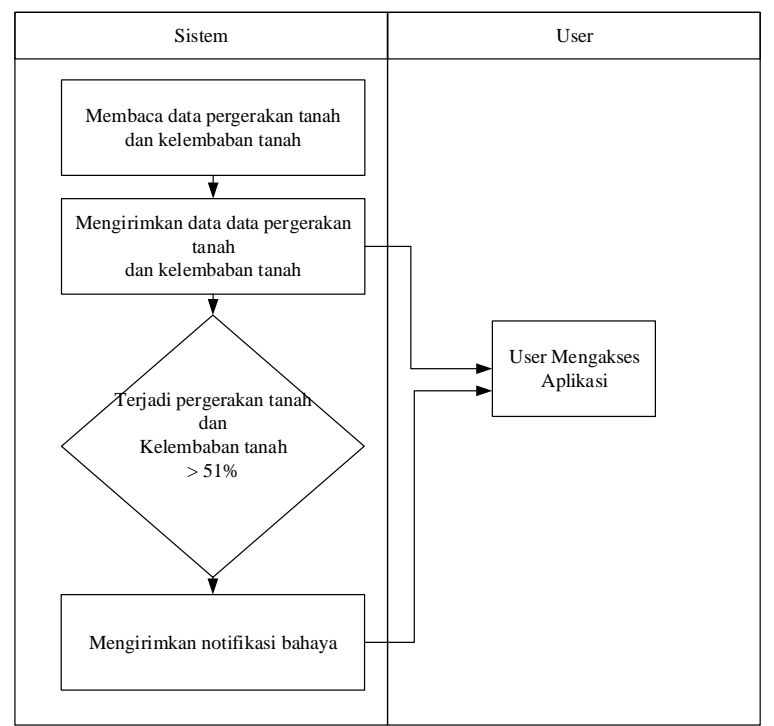

\section{Gambar 3.2 Rancangan Proses Secara Umum}

Gambar 3.2 menjelaskan alur sistem secara keseluruhan, dimana proses dimulai dari pembacaan data sensor dengan masukan beupa pergeseran tanah dan kelembaban tanah. Sensor MPU6050, sensor soil moisture dan NodeMcu diletakkan didalam kotak yang diberi tiang dan ditancapkan ke tanah.Sensor MPU6050 akan membaca pergerakan yang terjadi, sedangkan sensor soil moisture akan membaca kelembaban tanah. Kemusian NodeMcu sebagai mikrokontroler akan memproses input-an dari sensor. Ketika ada pergerakan tanah dan kelmbaban tanah lebih dari 51\%, maka notifikasi akan dikirimkan ke aplikasi android.

\subsection{Rancangan Perangkat Keras}

Pada tahapan ini langkah pertama yang dilakukan adalah merancang blok diagram. Blok diagram dari sistem peringatan dini bencana longsor ini dapat dilihat pada Gambar 3.3.

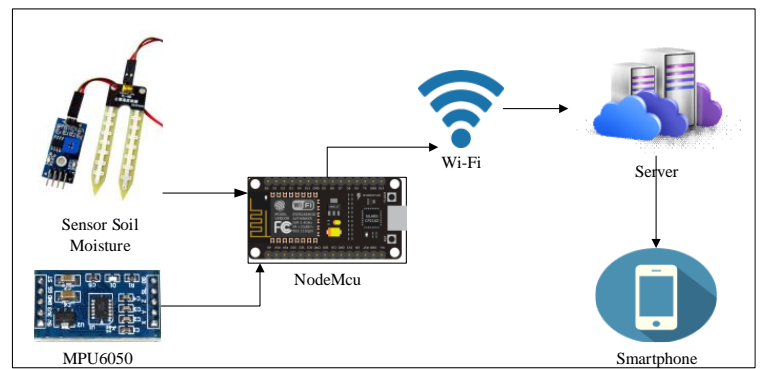

Gambar 3.3 Blok Diagram Perancangan Perangkat Keras

Adapun penjelasan dari blok diagram perancangan perangkat keras adalah:

1. Sensor accelerometer MPU6050 berfungsi membaca pergerakan tanah.

2. Sensor soil moisture berfungsi untuk membaca kelembaban tanah.

3. NodeMcu berfungsi sebagai mikrokontroler darisisten dan sebagai modul wifi.

4. Smartphone berfungsi untuk menampilkan notifikasi peringatan dini longsor.

\subsection{Rancangan Perangkat Lunak}

Perancangan perangkat lunak yang dibuat digunakan untuk mengatur kerja dari mikrokontroler yang merupakan pengontrol keseluruhan sistem peringatan dini bencana longsor dalam bentuk logika agar mikrokontroler dapat membaca data yang diterima dari sensor sehingga dapat menghasilkankeluaran dalam bentuk aplikasi mobile. Berikut adalah flowchart dari sistem peringatan dini bencana longsor berbasis android: 


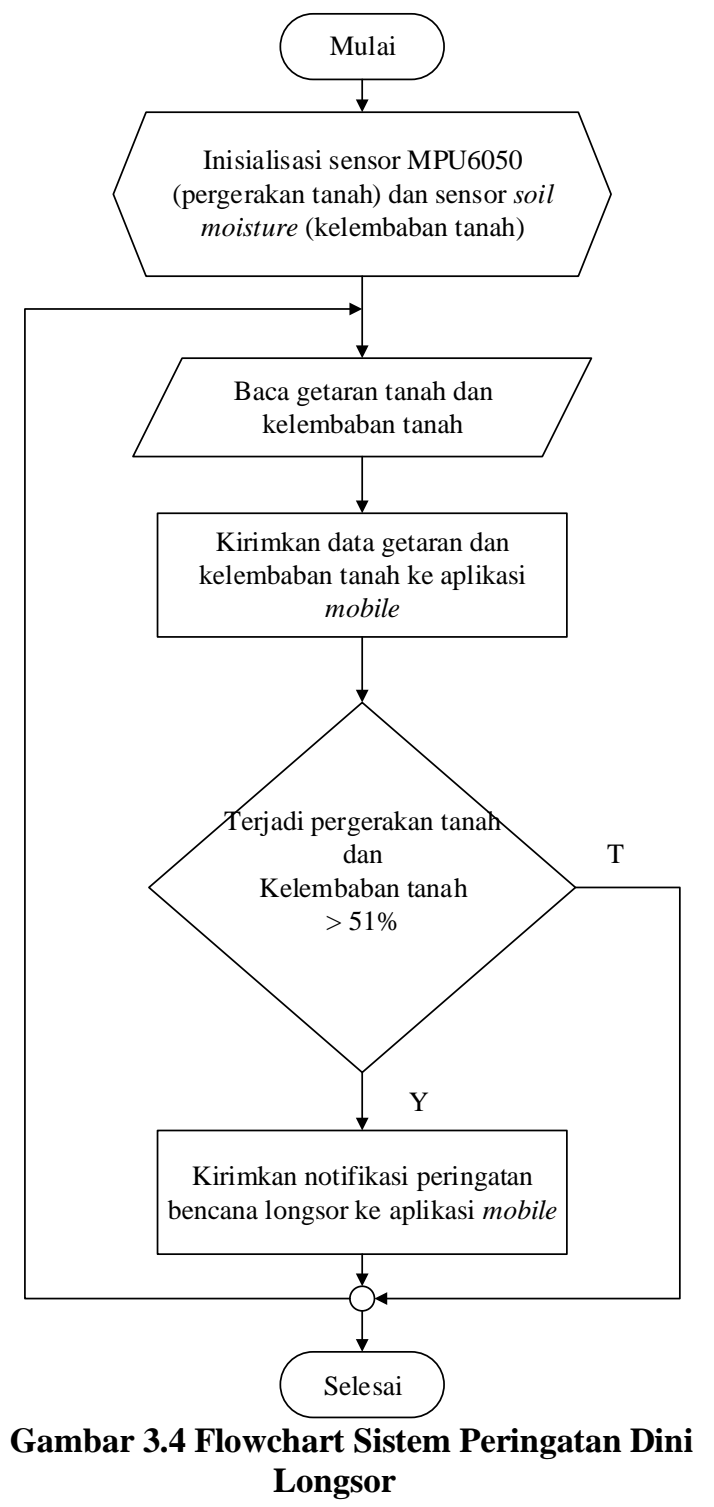

Pada gambar 3.4 dapat dilihat bahwa langkah-langkah dalam perancangan perangkat lunak dengan inisialisasi variabel yang dibutuhkan, kemudian pembacaan pergerakan tanah dan kelembaban tanah. Jika terjadi pergerakan tanah dengan range $\mathrm{x}$ besar dari 0.29 dan kecil dari 0.20 , y kecil dari 0.93 dan besar 1.01, serta z kecil dari 0.13 dan besar 0.00 dan kelembaban tanah leih dari $51 \%$ maka akan dikirim notifikasi pada android. Cara pengambilan range untuk sensor accelerometer adalah dengan mengambil beberapa data saat tonggak dari berdiri, digeser ke kanan, ke kiri, ke depan, dan ke belakang. Lalu di ambil data terkecil dan terbesar seperti yang dilakukan pada penelitian sebelumnya.

\section{HASIL DAN PEMBAHASAN}

\subsection{Implementasi Sistem}

Implementasi perangkat keras untuk penelitian ini dapat dilihat pada Gambar 4.1

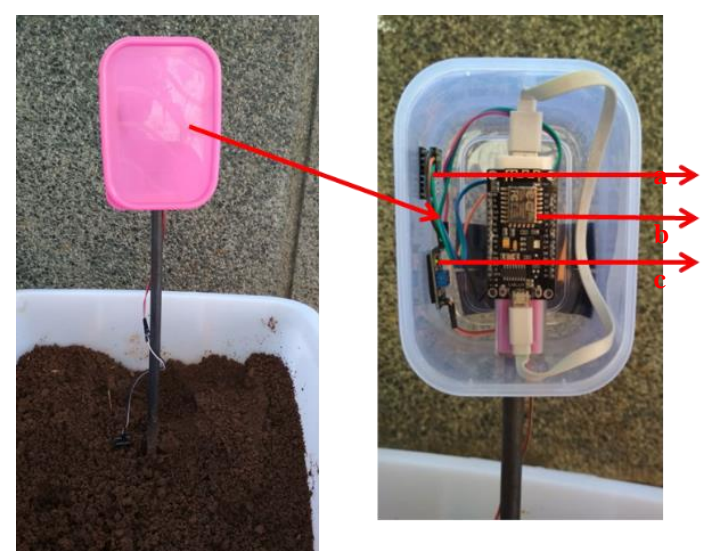

Gambar 4.1 Tampak Luar dan Tampak Dalam Implementasi Perangkat Keras

Keterangan gambar 4.1:

a. Sensor accelelerometer MPU6050 dugunakan untuk mengetahui pergeseran yang terjadi pada tanah.

b. Sensor soil moisture duhunakan untuk mengetahui kelembaban pada tanah.

c. NodeMcu digunakan sebagai mikrokontroler dan untuk mengirimkan data ke file penyimpanan.

\subsection{Pengujian Sistem}

Pengujian ini ditujukan untuk mengetahui kemampuan aplikasi dan perangkat keras untuk memberi peringatan dini bencana longsor.

\subsubsection{Pengujian Status Aman pada Kondisi Tanah} Diam dan Kelembaban Kurang dari $51 \%$

Pengujian ini dilakukan untuk mensimulasikan status aman dengan kondisi tanah diam dengan kelembaban tanah kurang dari $51 \%$. Pengambilan data untuk kondisi ini dengan sistem yang dilakukan sebanyak 10 kali dengan kondisi tanah yang kering dan diam. Gambar 4.3 merupakan gambar ketika prototype dalam kondisi aman dan tampilan pada android.

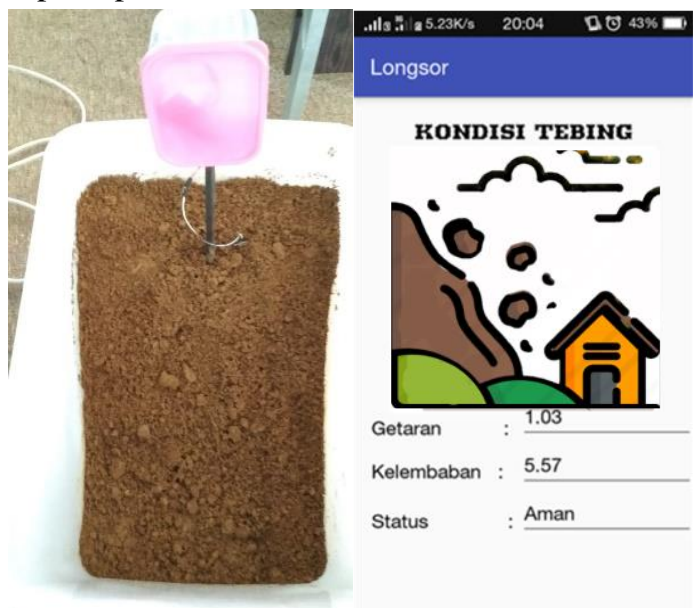

Gambar 4.3 Kondisi Prototype Aman Dan Tampilan Pada Android

Adapun hasil pengujian status aman dapat dilihat pada Tabel 4.1 di bawah. 
Tabel 4.1 Hasil Pengujian Status Aman

\begin{tabular}{|l|l|l|l|l|l|}
\hline No & $\begin{array}{l}\text { Kondisi } \\
\text { Tanah }\end{array}$ & $\begin{array}{l}\text { Kelembaban } \\
\text { Tanah }\end{array}$ & Status & $\begin{array}{l}\text { Waktu } \\
\text { Respon }\end{array}$ & Keterangan \\
\hline 1 & Diam & $8.34 \%$ & Aman & 2 detik & Berhasil \\
\hline 2 & Diam & $11.08 \%$ & Aman & 2 detik & Berhasil \\
\hline 3 & Diam & $11.09 \%$ & Aman & 2 detik & Berhasil \\
\hline 4 & Diam & $24.69 \%$ & Aman & 3 detik & Berhasil \\
\hline 5 & Diam & $24.69 \%$ & Aman & 2 detik & Berhasil \\
\hline 6 & Diam & $24.69 \%$ & Aman & 1 detik & Berhasil \\
\hline 7 & Diam & $25.01 \%$ & Aman & 2 detik & Berhasil \\
\hline 8 & Diam & $25.11 \%$ & Aman & 2 detik & Berhasil \\
\hline 9 & Diam & $25.11 \%$ & Aman & 2 detik & Berhasil \\
\hline 10 & Diam & $31.78 \%$ & Aman & 2 detik & Berhasil \\
\hline
\end{tabular}

Berdasarkan pengujian yang telah dilakukan untuk status aman, dapat disimpulkan bahwa sistem dapat mengidentifikasi status aman dengan persentase keberhasilan $100 \%$ dengan rata-rata waktu respon adalah 2 detik.

\subsubsection{Pengujian Status Bahaya pada Kondisi Tanah Diam dan Kelembaban Lebih Dari 51\%}

Pengujian ini dilakukan untuk mensimulasikan staus bahaya dengan kondisi tanah diam dengan kelembaban tanah lebih dari $51 \%$. Pengambilan data untuk kondisi ini dengan sistem yang dibuat sebanyak 10 kali. Untuk mendapatkan status bahaya dengan kelembaban lebih dari 51\%, maka dilakukan simulasi dengan menyiramkan air ke prototype longsor yang telah dibuat. Gambar 4.4 merupakan gambar ketika prototype dalam kondisi bahaya dan tampilan pada android.
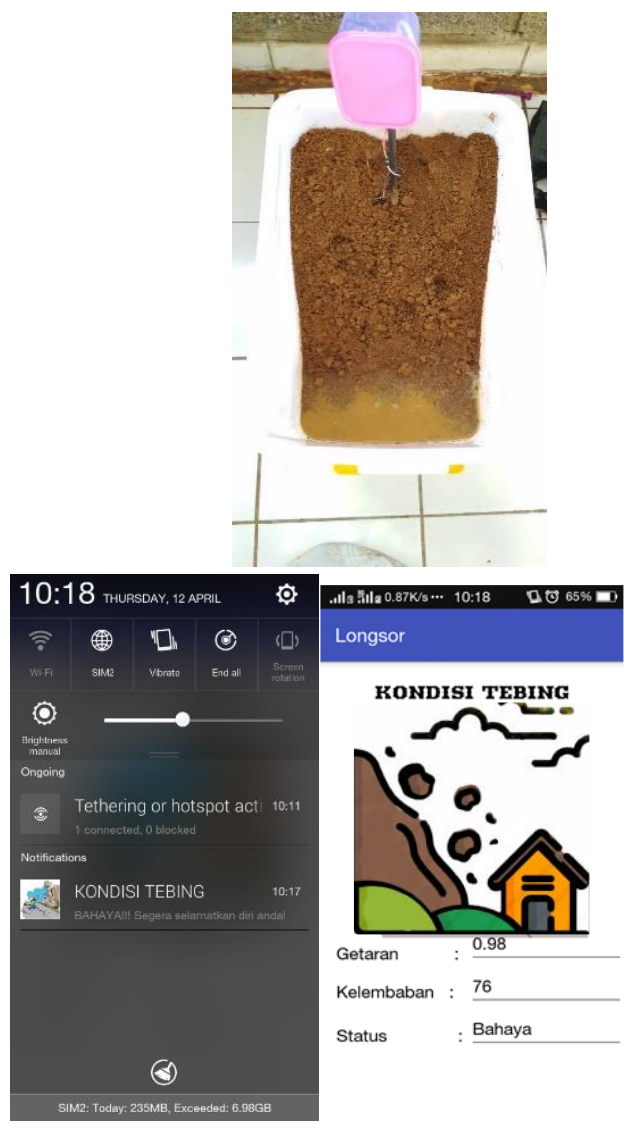

Gambar 4.4 Kondisi Prototype Bahaya Dan Tampilan Pada Android
Adapun hasil pengujian status bahaya pada kondisi tanah dian dan kelembaban lebih dari $51 \%$ dapat dilihat pada Tabel 4.2 di bawah.

Tabel 4.2 Hasil Pengujian Posisi Berjalan

\begin{tabular}{|l|l|l|l|l|l|}
\hline No & $\begin{array}{l}\text { Kondisi } \\
\text { Tanah }\end{array}$ & $\begin{array}{l}\text { Kelembaban } \\
\text { Tanah }\end{array}$ & Status & $\begin{array}{l}\text { Waktu } \\
\text { Respon }\end{array}$ & Keterangan \\
\hline 1 & Diam & $53.04 \%$ & Bahaya & 2 detik & Berhasil \\
\hline 2 & Diam & $53.04 \%$ & Bahaya & 2 detik & Berhasil \\
\hline 3 & Diam & $56.30 \%$ & Bahaya & 2 detik & Berhasil \\
\hline 4 & Diam & $56.37 \%$ & Bahaya & 2 detik & Berhasil \\
\hline 5 & Diam & $56.38 \%$ & Bahaya & 2 detik & Berhasil \\
\hline 6 & Diam & $60.57 \%$ & Bahaya & 3 detik & Berhasil \\
\hline 7 & Diam & $60.72 \%$ & Bahaya & 3 detik & Berhasil \\
\hline 8 & Diam & $61.36 \%$ & Bahaya & 2 detik & Berhasil \\
\hline 9 & Diam & $61.97 \%$ & Bahaya & 2 detik & Berhasil \\
\hline 10 & Diam & $63.03 \%$ & Bahaya & 2 detik & Berhasil \\
\hline
\end{tabular}

Berdasarkan pengujian yang telah dilakukan untuk status bahaya, dapat disimpulkan bahwa sistem dapat mengidentifikasi status bahaya dengan persentase keberhasilan $100 \%$ dengan rata-rata waktu respon adalah 2.2 detik.

\subsubsection{Pengujian Status Bahaya pada Kondisi Tanah dengan Kelembaban Kurang dari $51 \%$ dan Terjadi Pergeseran Tanah}

Pengujian ini dilakukan untuk mensimulasikan status bahaya dengan kondisi tanah dengan kelembaban tanah kurang dari 51\% dan adanya pergeseran tanah. Pengambilan data untuk kondisi ini dengan sistem yang dibuat sebanyak 10 kali. Untuk mendapatkan status bahaya dengan kondisi terjadi pergerakan tanah, maka dilakukan simulasi dengan menggerakkan tonggak penampang alat sitem peringatan dini bencana longsor. Gambar 4.5 merupakan gambar ketika prototype dalam kondisi bahaya dan tampilan pada android.

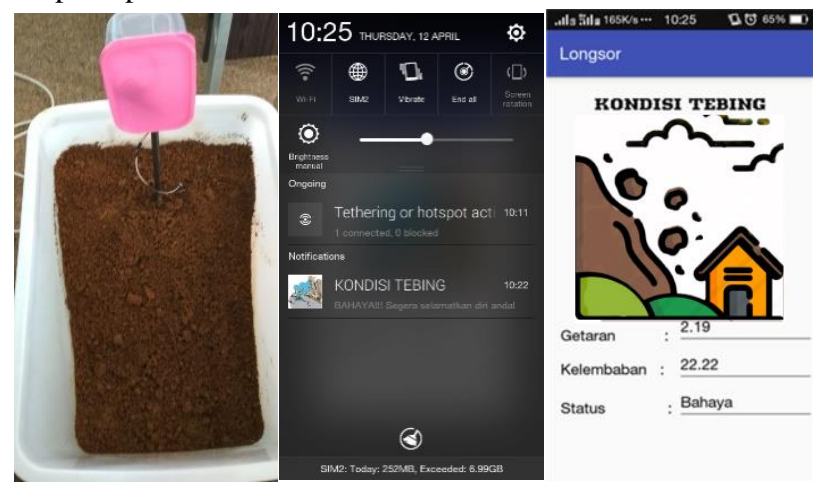

Gambar 4.5 Kondisi Prototype Bahaya Dan Tampilan Pada Android

Adapun hasil pengujian status bahaya dengan kelembaban tanah kurang dari $51 \%$ dan ada pergeseran tanah dapat dilihat pada Tabel 4.3 di bawah. 
Tabel 4.3 Hasil Pengujian Posisi Duduk

\begin{tabular}{|l|l|l|l|l|l|}
\hline No & $\begin{array}{l}\text { Kondisi } \\
\text { Tanah }\end{array}$ & $\begin{array}{l}\text { Kelembaban } \\
\text { Tanah }\end{array}$ & Status & $\begin{array}{l}\text { Waktu } \\
\text { Respon }\end{array}$ & Keterangan \\
\hline 1 & Bergerak & $11.21 \%$ & Bahaya & 3 detik & Berhasil \\
\hline 2 & Bergerak & $21.74 \%$ & Bahaya & 2 detik & Berhasil \\
\hline 3 & Bergerak & $23.53 \%$ & Bahaya & 2 detik & Berhasil \\
\hline 4 & Bergerak & $43.82 \%$ & Bahaya & 1 detik & Berhasil \\
\hline 5 & Bergerak & $43.89 \%$ & Bahaya & 3 detik & Berhasil \\
\hline 6 & Bergerak & $44.13 \%$ & Bahaya & 3 detik & Berhasil \\
\hline 7 & Bergerak & $44.68 \%$ & Bahaya & 3 detik & Berhasil \\
\hline 8 & Bergerak & $44.83 \%$ & Bahaya & 2 detik & Berhasil \\
\hline 9 & Bergerak & $49.32 \%$ & Bahaya & 2 detik & Berhasil \\
\hline 10 & Bergerak & $49.46 \%$ & Bahaya & 1 detik & Berhasil \\
\hline
\end{tabular}

Berdasarkan pengujian yang telah dilakukan untuk status bahaya, dapat disimpulkan bahwa sistem dapat mengidentifikasi status bahaya dengan persentase keberhasilan $100 \%$ dengan persentase rata-rata 2.2 detik

\subsubsection{Pengujian Status Bahaya pada Kondisi Tanah dengan Kelembaban Lebih Dari $51 \%$ dan Terjadi Pergeseran Tanah.}

Pengujian ini dilakukan untuk mensimulasikan status bahaya dengan kondisi tanah dengan kelembaban tanah lebih dari 51\% dan terjadi pergeseran tanah. Pengambilan data untuk kondisi ini dengan sistem yang dibuat sebanyak 10 kali. Untuk mendapatkan status bahaya dengan kelembaban lebih dari $51 \%$ dan terjadi pergeseran tanah, maka dilakukan simulasi dengan menyiramkan air ke prototype longsor yang telah dibuat dan menggerakkan tonggak dari alat peringatan dini longsor. Gambar 4.6 merupakan gambar ketika prototype dalam kondisi bahaya dan tampilan pada android.

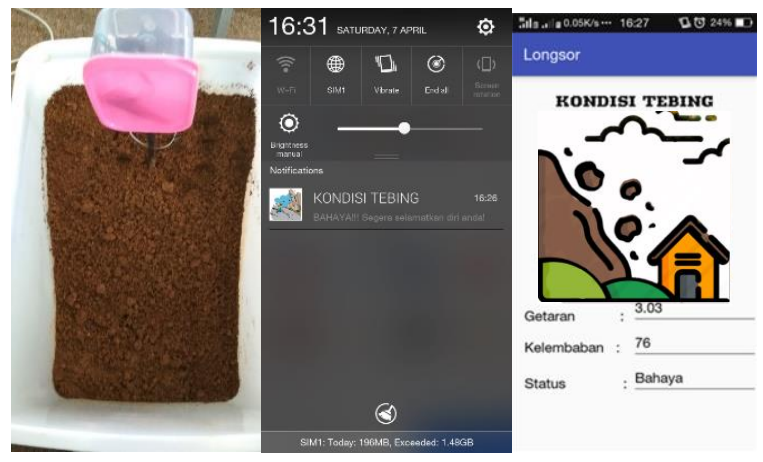

Gambar 4.6 Kondisi Prototype Bahaya Dan Tampilan Pada Android

Adapun hasil pengujian bahaya pada kondisi tanah dengan kelembaban lebih dari $51 \%$ dan terjadi pergeseran tanah dapat dilihat pada Tabel 4.4 di bawah.

Berdasarkan pengujian yang telah dilakukan untuk status bahaya, dapat disimpulkan bahwa sistem dapat mengidentifikasi status bahaya dengan persentase keberhasilan $100 \%$ dengan rata-rata waktu respon 1.9 detik.
Tabel 4.4 Hasil Pengujian Posisi Duduk Jatuh ke Kanan

\begin{tabular}{|l|l|l|l|l|l|}
\hline No & $\begin{array}{l}\text { Kondisi } \\
\text { Tanah }\end{array}$ & $\begin{array}{l}\text { Kelembaban } \\
\text { Tanah }\end{array}$ & Status & $\begin{array}{l}\text { Waktu } \\
\text { Respon }\end{array}$ & Keterangan \\
\hline 1 & Bergerak & $52.22 \%$ & Bahaya & 1 detik & Berhasil \\
\hline 2 & Bergerak & $52.74 \%$ & Bahaya & 3 detik & Berhasil \\
\hline 3 & Bergerak & $52.89 \%$ & Bahaya & 2 detik & Berhasil \\
\hline 4 & Bergerak & $53.56 \%$ & Bahaya & 1 detik & Berhasil \\
\hline 5 & Bergerak & $56.82 \%$ & Bahaya & 2 detik & Berhasil \\
\hline 6 & Bergerak & $57.21 \%$ & Bahaya & 2 detik & Berhasil \\
\hline 7 & Bergerak & $57.71 \%$ & Bahaya & 2 detik & Berhasil \\
\hline 8 & Bergerak & $61.84 \%$ & Bahaya & 2 detik & Berhasil \\
\hline 9 & Bergerak & $63.09 \%$ & Bahaya & 2 detik & Berhasil \\
\hline 10 & Bergerak & $63.43 \%$ & Bahaya & 2 detik & Berhasil \\
\hline
\end{tabular}

\section{KESIMPULAN DAN SARAN}

\subsection{Kesimpulan}

Berdasarkan perancangan, pengamatan dan pengujian yang telah dilakukan dapat diambil kesimpulan sebagai berikut :

1. Sensor MPU6050 dapat membaca data pergerakan tanah dengan persentase error sebesar $0.42 \%$.

2. Sensor Soil Moisture dapat membaca kelembaban tanah dengan persentase error sebesar $1.49 \%$.

3. Sistem dapat memberikan notifikasi berisi informasi kondisi tebing menggunakan smartphone dengan persentase keberhasilan sebesar $100 \%$.

\subsection{Saran}

Mengingat masih terdapat kekurangan pada penelitian ini, maka perlu dilakukan beberapa perbaikan untuk memperbaiki kinerja sistem, adapun beberapa saran yang diperlukan antara lain.

1. Untuk penelitian selanjutnya, dalam menentukan lokasi longsor sebaiknya menambahkan modul GPS sehingga lokasi longsor dapat diketahui secara langsung.

Pada penelitian selanjutnya agar dapat terhubung dengan Badan Penanggulangan Bencana Daerah (BPBD), sehingga Badan Penanggulangan Bencana Daerah (BPBD) mendapatkan notifikasi keadaan tebing.

\section{REFERENSI}

[1] Nugroho, Sutopo Purwo, M.Si, APU. 2016. Evaluasi Penanggulangan Bencana 2015 Dan Prediksi Bencana 2016. Badan Nasional Penanggulangan Bencana. Jakarta

[2] Zakaria, Z. 2013. Analisis Kestabilan Lereng Tanah. Year Book Mitigasi Bencana, Jakarta.

[3] Mardhatillah, Elvira, S.Si. 2017. Rancang Bangun Sistem Peringatan Dini Tanah Longsor Berbasis Mikrokontroler Atmega328 Menggunakan Metode Penginderaan Berat. Universitas Andalas. Padang

[4] Susilo, Adi. Didik R. Santoso, Arief Rachmansyah, Yulvi Zaika. 2011. Desain Sistem Peringatan Dini Zona Rawan Longsor Dengan Penerapan Sensor Kelembaban Dan Getaran Pada Tanah.

[5] Sutikno, 2011, Mengenal Tanah Longsor, Direktorat Geologi Tata Lingkungan Departemen Pertambangan dan Energi, Bandung. 
[6] Karnawati, D. 2005. Bencana Alam Gerakan Massa Tanah di Indonesia dan Upaya Penanggulangannya. Jurusan Teknik Geologi, Universitas Gadjah Mada, Indonesia.

[7] Karnawati, D, 2011, Bencana Alam Gerakan Tanah Indonesia Tahun 2000, Universitas Gadjah Mada , Yogyakarta.

[8] Wirawan, Rahadi, dkk, 2016, Rancang Bangun Sistem Pendeteksi Tanah Longsor Sederhana Berbasis Sensor Soil Moisture dan Sensor Ultrasonik, Univresitas Mataram, Mataram.

[9] NodeMCUTeam. 2014. NodeMCU connect thing easy.http://www.nodemcu.com/index_en.html diakses pada tanggal 20 Juli 22:12 WIB

[10] Inven Sense. Inc. 2013. MPU-6000 and MPU-6050 Product Specification Revision 3.4

[11] Caesar, P. Y., Isnawaty, dan Fid A. (2016), Rancang bangun Prototype System Monitoring Kelembaban Tanah Melalui SMS Berdasarkan Hasil Penyiraman Tanaman "Studi Kasus Tanaman Cabai dan Tomat"

[12] Indoware, 2015, Soil Moisture sensor,http://indo-ware.com/produk284-moisture-sensor-.html, diakses pada12 Desember 2017.

[13] Chinetha, K, J.Daphney Joann dan A.Shalini. 2015. An Evolution of Android Operating System and Its Version. IJEAS. 2: 30-33

[14] M. Dongre, Nikhil, Tejas S. Agrawal., Sagar D. Pande. 2017. A Research On Android Technology With New Version Naugat(7.0,7.1). (IOSR-JCE).

[15] Yuniar, Supardi.2014.Semua Bisa Menjadi Programmer Android. Elex Media. Bandung.

[16] Supriyadi, Daud Febrizer, 2016, Sistem Monitoring Pergeseran Tanah Terhadap Potensi Longsor Secara Wireless Berbasis Mikrokontroler, Universitas Airlangga, Surabaya.

[17] Jian He, Chen Hu, Xiaoyi Wang. 2016. A Smart Device Enabled System for Autonomous Fall Detection and Alert. International Journal of Distributed Sensor Networks.

[18] Walin, Fu, H. Zhao, Y. Zhao, H. Zhong. 2015. Development of a wearable-sensor-based fall detection systems. International Journal of Telemedicine and Applications.

[19] Stevanus dan Setiadi, K.. D., 2013, Alat Pengukur Kelembaban Tanah Berbasis Mikrokontroler Pic 16f84, Jurnal Teknik Elektro Universitas Kristen Maranatha,Bandung. 